\title{
¿CÓMO INTRODUCIR EL CRISTIANISMO \\ DENTRO DE LA CRISTIANDAD? \\ COMUNICACIÓN INDIRECTA, SEUDÓNIMOS E IRONÍA EN KIERKEGAARD
}

Luis Guerrero M.

Universidad Iberoamericana, México

\section{Resumen}

El propósito de este ensayo es hacer un breve recorrido por lo que considero las motivaciones más profundas entre el método empleado por Kierkegaard como escritor y la percepción de su misión histórica. Este recorrido comienza con la figura paradigmática de Sócrates, lo que permitirá, a fin de cuentas, ahondar en la importancia y significado del texto kierkegaardiano: "La cristiandad es un inmenso espejismo", que forma parte de su libro póstumo El punto de vista sobre mi obra como escritor.

Palabras clave: Sócrates, ironía, comunicación indirecta, crítica histórica, cristiandad.

\section{Abstract}

The purpose of this essay is to give an insight of what I consider the deepest motivations within the method used by Kierkegaard as a writer and the perception of his historical mission. This insight begins with the paradigmatic figure of Socrates; this will allow, at the end, to deepen into the importance and meaning of the Kierkegaardian text: "Christendom Is an Enormous Illusion", which is part of his posthumous book The Point of View for My Work as an Author.

Key words: Socrates, irony, indirect communication, historical criticism, Christendom.

"Existe un pájaro que se llama «augur de lluvias» [Regnspaaer]; yo soy como ese pájaro. En nuestra generación, cuando se prepara una tormenta, los individuos de mi clase aparecen"1.

Søren Kierkegaard

${ }^{1}$ Søren Kierkegaard, Papirer, SKS 18, 271, JJ:231. 
“Tendrás la sensatez de no creer que sabes lo que ignoras"2.

Sócrates

Cuando en 1849 Kierkegaard escribió El punto de vista sobre mi obra como escritor, en la cual realizó una breve mirada sobre su época y sus escritos, tuvo en cuenta exclusivamente sus obras seudónimas y sus discursos edificantes, sin hacer casi referencia alguna a sus escritos de juventud. Sin embargo, el planteamiento que hace en ese escrito, y especialmente en el apartado "La cristiandad es una prodigiosa ilusión", permite hacer una conexión con toda su obra desde su época de estudiante hasta sus últimos escritos. Esta conexión está sostenida por su temprano interés en la ironía socrática y en la forma indirecta que el mismo Sócrates usó como método mayéutico.

Al elaborar su tesis universitaria Sobre el concepto de ironía en constante referencia a Sócrates, Kierkegaard tuvo una profunda experiencia sobre la ironía socrática y el papel que tuvo en la filosofía griega. Los años en los que preparó ese trabajo supusieron para él una forma distinta de entender el papel de la filosofía, como una forma de contribuir al desmantelamiento de los diversos espejismos en los que su época había caído. En este estudio analizaré la importancia de la ironía socrática en la génesis de la vocación de Kierkegaard como escritor y la influencia del método mayéutico en el propio método kierkegaardiano, ejemplificando esto último a través del planteamiento de sus obras seudónimas La enfermedad mortal y Ejercitación del cristianismo.

\section{La ironía socrática}

Tal vez el texto más significativo del método socrático, llamado por

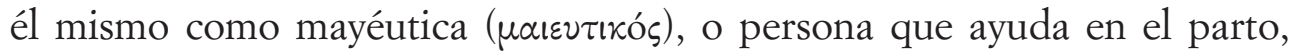
se encuentra en el diálogo platónico Teeteto, que versa sobre la naturaleza del saber. Sócrates reconoce inicialmente su ignorancia sobre la naturaleza del saber: "Esto es lo que me deja perplejo: no soy capaz de comprender adecuadamente por mí mismo qué es realmente el saber" ${ }^{3}$, a partir de lo cual comienza el diálogo con Teeteto, quien propone sucesivamente

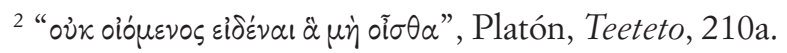

${ }^{3}$ Platón, Teeteto, 145e. 
tres definiciones del saber. Por medio de la habitual forma dialéctica de proceder de Sócrates, ambos terminan por reconocer que ninguna de las tres definiciones ensayadas es aceptable. Es en estas circunstancias donde Sócrates habla de la mayéutica. La referencia al método se hace en dos momentos, el primero de ellos, al comienzo del diálogo, cuando Teeteto también manifiesta su imposibilidad para definir qué es el saber y cumplir con las exigencias de Sócrates. Esta dificultad da ocasión a Sócrates para hablar acerca del arte mayéutico. La segunda referencia se hace al final del diálogo, cuando ambos, Teeteto y Sócrates, nuevamente reconocen que no han podido llegar a la definición del saber, lo que, una vez más, permite a Sócrates hablar del propósito de la mayéutica. Si bien ambas referencias son igualmente importantes, la última tiene una mayor relevancia para comprender la influencia del método socrático en la génesis del pensamiento de Kierkegaard.

Sócrates - Si investigamos qué es el saber, es completamente estúpido decir que es la recta opinión acompañada del saber, ya sea de la diferencia o de cualquier otra cosa. Por tanto, Teeteto, resulta que el saber no sería ni percepción, ni opinión verdadera, ni explicación acompañada de opinión verdadera.

Teeteto - Parece que no.

Sócrates - Querido amigo, ¿estamos todavía en condiciones de dar a luz y de experimentar los dolores del parto, con relación al saber, o es que hemos ya parido del todo?

Teeteto - Sí, por Zeus, yo, al menos, gracias a ti he dicho más de lo que albergaba en mi interior.

Sócrates - ¿No nos dice nuestro arte de partear que todo esto ha resultado ser algo vacío y que no merece nuestro cuidado?

Teeteto - Sin duda alguna.

Sócrates - Pues bien, Teeteto, si después de esto intentaras concebir y llegaras a conseguirlo, tus frutos serían mejores gracias al examen que acabamos de hacer, y si quedas estéril, serás menos pesado y más tratable para tus amigos, pues tendrás la sensatez de no creer que sabes lo que ignoras. Esto, efectivamente, y nada más es lo único que mi arte puede lograr. Yo nada sé de esos conocimientos que poseen tantos grandes y admirables hombres del presente y del pasado. Sin embargo, mi madre y yo hemos recibido de Dios este arte de los partos y lo practicamos, ella, con las mujeres, y yo, con los jóvenes de noble condición y con todos aquellos en los que pueda hallarse la belleza ${ }^{4}$.

\footnotetext{
${ }^{4}$ Platón, Teeteto, 210a.
} 
Destacan dos aspectos relevantes en el fragmento citado. En primer lugar, como en otros diálogos aporéticos, no se llega a un conocimiento acerca de la definición que se quiere dilucidar. Tanto Sócrates como Teeteto llegan a esta conclusión. En el caso de Sócrates, esta ignorancia no es de sorprender, pues él mismo había declarado su incapacidad para comprender qué es el saber. Al inicio del diálogo, en la primera referencia a la mayéutica, Sócrates comenta que las mujeres que ejercen el oficio de partera lo hacen cuando ya no son susceptibles de preñez, a lo que Sócrates comenta:

Tengo igualmente, en común con las parteras esta característica: que soy estéril en sabiduría. Muchos, en efecto, me reprochan que siempre pregunto a otros y yo mismo nunca doy ninguna respuesta acerca de nada por mi falta de sabiduría, y es, efectivamente, un justo reproche. La causa de ello es que el dios me obliga a asistir a otros, pero a mí me impide engendrar. Así es que no soy sabio en modo alguno, ni he logrado ningún descubrimiento que haya sido engendrado por mi propia almas.

El segundo aspecto a considerar es la relevancia que Sócrates le da a la mayéutica. De entre los motivos que da, tal vez el más importante es que por medio de ella se puede obtener "la sensatez de no creer que sabes lo que ignoras". Este reconocimiento de la ignorancia posibilita un mejor modo de enfrentar el problema, ya sea para indagar mejor acerca de la naturaleza del saber, o para tener una actitud menos pesada y más tratable para los demás. "Esto, -concluye Sócrates- efectivamente, y nada más es lo único que mi arte puede lograr".

Este reconocimiento del falso saber es uno de los aspectos centrales que, a mi entender, interesaron a Kierkegaard. Cuando en El punto de vista sobre mi obra como escritor señala el espejismo común de creer que se es cristiano, cuando en realidad se vive en categorías muy apartadas de lo cristiano, también señala la dificultad de que los que viven en el espejismo reconozcan su verdadera situación, por lo que, concluye Kierkegaard, es necesaria la comunicación indirecta. Puede observarse el paralelismo entre el propósito de la mayéutica socrática y la comunicación indirecta en Kierkegaard, en ambos casos se busca que el interlocutor o el lector, que de alguna manera creen estar en una situación en la que no están, caigan en cuenta de su verdadera situación.

Platón muestra en diversas ocasiones este propósito de la mayéutica socrática. Uno de esos ejemplos se encuentra en distintos momentos del

${ }^{5}$ Platón, Teeteto, $150 \mathrm{~b}$. 
Menón, que aborda el tema de la virtud, buscando su definición y si puede ser enseñada o no. El diálogo nos presenta tres interlocutores de Sócrates, el mismo Menón, un sirviente y Anito. Los tres tienen en común creer que saben algo que en realidad desconocen. A partir de este hecho se desarrolla la dialéctica cargada de ironía de Sócrates. En el caso de Menón, después de ensayar infructuosamente tres definiciones de lo que es la virtud, termina por reconocer:

Menón - ¡Ah... Sócrates! Había oído yo, aun antes de encontrarme contigo, que no haces tú otra cosa que problematizarte y problematizar a los demás. Y ahora, según me lo parece, me estás hechizando, embrujando y hasta encantando por completo al punto que me has reducido a una madeja de confusiones. Y si se me permite hacer una pequeña broma, diría que eres parecidísimo, por tu figura como por lo demás, a ese chato pez marino, el torpedo. También él, en efecto, entorpece al que se le acerca y lo toca, y me parece que tú ahora has producido en mí un resultado semejante. Pues, en verdad, estoy entorpecido de alma y de boca, y no sé qué responderte. Sin embargo, miles de veces he pronunciado innumerables discursos sobre la virtud, también delante de muchas personas, y lo he hecho bien, por lo menos así me parecía. Pero ahora, por el contrario, ni siquiera puedo decir qué es ${ }^{6}$.

Como puede observarse, Menón ha tenido que reconocer que aquello que creía saber sobre la virtud, y gracias a lo cual no encontraba ninguna dificultad para definirla ante los demás, ahora se ha tornado en una madeja de confusiones, tocado por el pez torpedo ${ }^{7}$. Más adelante en el diálogo aparece la figura del sirviente, quien es interrogado para mostrarle a Menón el modo de resolver el dilema sobre el reconocimiento del saber. En ese diálogo con el sirviente, vuelve a aparecer la falsa creencia del conocimiento:

Sócrates - ¿Ves Menón, que yo no le enseño nada, sino que le pregunto todo? Y ahora él cree saber ${ }^{8}$.

Sin embargo, el esclavo no sabe y nuevamente la mayéutica produce su efecto, hasta que el sirviente reconoce:

Servidor - ¡Por Zeus, Sócrates, que yo no lo sé!?

${ }^{6}$ Platón, Menón, 80a.

${ }^{7} \mathrm{El}$ pez torpedo es un tipo de raya, capaz de producir fuertes descargas eléctricas que usa para capturar a sus presas y para defenderse.

${ }^{8}$ Platón, Menón, 80e.

9 Platón, Menón, 84a. 
A partir de este reconocimiento de la ignorancia por parte del esclavo, Sócrates realiza una significativa reflexión con Menón, precisamente sobre la importancia del método mayéutico, reflexión que concuerda con las palabras del mismo Sócrates en el Teeteto:

Sócrates - Te das cuenta una vez más, Menón, en qué punto se encuentra ya del camino de la reminiscencia porque al principio no sabía cuál era la línea de la superficie de ocho pies, como tampoco ahora lo sabe aún; sin embargo, creía entonces saberlo y respondía con la seguridad propia del que sabe, considerando que no había problema. Ahora, en cambio, considera que está ya en el problema, y como no sabe la respuesta, tampoco cree saberla.

Menón - Es verdad.

Sócrates - ¿Entonces está ahora en una mejor situación con respecto del asunto que no sabía?

Menón - Así me parece.

Sócrates - Al problematizarlo y entorpecerlo, como hace el pez torpedo, ¿le hicimos algún daño?

Menón - A mí me parece que no.

Sócrates - Le hemos hecho, al contrario, un beneficio Para resolver cómo es la cuestión. Ahora, en efecto, buscará de buen grado, puesto que no sabe, mientras que muchas veces antes, delante de todos, con tranquilidad, creía estar en lo cierto al hablar de la superficie doble y suponía que había que partir de una superficie del doble de largo.

Menón - Así me parece.

Sócrates - ¿Crees acaso que él hubiera tratado de buscar, aprender esto que creía que sabía, pero ignoraba, antes de verse problematizado y convencido de no saber, y de sentir el deseo de saber?

Menón - Me parece que no, Sócrates.

Sócrates - ¿Ha ganado, entonces, al verse entorpecido?

Menón - Así me parece ${ }^{10}$.

El tercer interlocutor de Sócrates en el Menón es Anito, quien sería a la postre uno de los testigos para la condena de Sócrates. Ante la pregunta de si sabe quién puede ser maestro de la virtud. Anito responde con seguridad:

Anito - ¿Y por qué quieres oír el nombre de uno solo? Cualquiera de los atenienses bellos y buenos con que se encuentre, sin excepción, lo harán un hombre virtuoso, de una manera mejor -siempre que les haga caso- que lo que los sofistas hacen ${ }^{11}$.

${ }^{10}$ Platón, Menón, 84a.

${ }^{11}$ Platón, Menón, 92e. 
La ironía de Sócrates desarrollada en esta parte del diálogo es incluso un tanto mordaz. Pues Sócrates comienza alabando por sus cualidades al padre de Anito, para después hacer caer en cuenta a su interlocutor que muchos de los padres "bellos y buenos" no han sabido educar a sus hijos. Anito también siente los efectos del pez torpedo y termina muy irritado, antes de marcharse expresa su disgusto en un tono amenazador:

Anito - ¡Ah... Sócrates! Me parece que fácilmente hablas mal de los demás. Yo te aconsejaría, si me quieres hacer caso, que te cuidaras: porque, del mismo modo que en cualquier otra ciudad es fácil hacer mal o bien a los hombres, en ésta lo es en modo muy particular. Creo que también tú lo sabes ${ }^{12}$.

Con un aire resignado, Sócrates le comenta a Menón que Anito en realidad no sabe lo que significa hablar mal de alguien, pues si lo supiera dejaría de irritarse. Como puede observarse, una y otra vez en los distintos diálogos, la mayéutica socrática busca que sus interlocutores caigan en la cuenta de su situación, para que tengan "la sensatez de no creer saber lo que en realidad se ignora".

Esta sensatez es la que también quiere provocar Kierkegaard dentro de la cristiandad, pues está sumida en un terrible espejismo, en el que todos creen estar en el camino adecuado, aunque en realidad no lo estén. Por eso se pregunta ¿Cómo destruir este espejismo? ¿Cómo aplicar la dieta socrática, en este caso, el lograr que los demás reconozcan que su vida transcurre en categorías muy alejadas del cristianismo? Ante la posible objeción que destruir un espejismo es una tarea condenada al fracaso, Kierkegaard concluye: "Esta objeción no se aprendió de Sócrates; porque él se relacionó con la "muchedumbre" y quiso reformarla"13. Este ejemplo socrático es lo que marcó a Kierkegaard en la génesis y en el desarrollo de su actividad como escritor, y de esta forma puede comprenderse mejor el despliegue de recursos literarios: la comunicación indirecta, el uso de seudónimos, la ironía, los estadios de la existencia, etc.

\section{La ironía socrática en Kierkegaard}

La primera referencia de Kierkegaard a la ironía socrática, en el sentido que se mencionó en el apartado anterior, se encuentra en la famosa carta

12 Platón, Menón, 94e.

13 Søren Kierkegaard, "La 'cristiandad' es un inmenso espejismo", trad. de Leticia Valadez / SKS 16, 24. 
de Gilleleje del primero de agosto de 1835. En esta carta, que versa sobre la importancia y búsqueda del fundamento interior, aquello que permite encontrar una base sólida por lo cual vivir y morir, Kierkegaard señala que

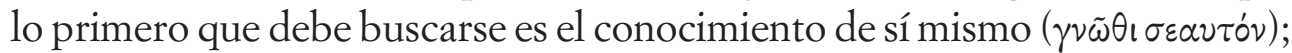
gracias a esta búsqueda uno puede arreglar cuentas con la ironía de la vida en el ámbito del conocimiento, que "invita al verdadero conocimiento, el cual se origina en el no-conocimiento (Sócrates)" ${ }^{14}$.

Esta alusión a la ironía está enmarcada en una discusión histórica, más amplia, sobre la importancia de la ironía en la producción estética, en la crítica social y en la reacción contra la Ilustración y el racionalismo. Importante antecesor del Sturm und Drang y del Romanticismo, J. G. Hamann introdujo en 1759 una renovada interpretación de Sócrates con sus Memorabilia socratica, no solamente para exponer algunos rasgos de su pensamiento sino, sobre todo, para hacer uso de la ironía en contra de los excesos de la sociedad del siglo XVIII, especialmente en el ámbito de la filosofía, todo esto por medio de su peculiar estilo retórico, en donde abundan las analogías, metáforas y las críticas indirectas llenas de ironía.

Así como Sócrates ejerció con los jóvenes el arte heredado de su madre, también "Sócrates imitó a su padre, un escultor, quien, al quitar y tallar lo que no debe estar en la madera, promueve por ello la forma de la imagen. De ahí que los grandes hombres de su tiempo tuvieran motivo suficiente para quejarse diciendo que estaba derribando todos los robles de sus bosques, estropeando todos sus troncos y que de su madera no sabía hacer más que virutas" 15 .

Hamann remarca que la ironía socrática es connatural al reconocimiento de la ignorancia, mediante la capacidad de observar la magnitud de la realidad $y$, en contraste, las limitaciones del entendimiento. Este reconocimiento le permite jugar con una inusitada fuerza con la falsa sabiduría de aquellos que se ostentaban como los sabios y educadores de la sociedad.

La opinión de Sócrates se puede resumir en estas palabras ásperas que dirigió a los sofistas, a los doctos de su tiempo: "No sé nada". De hecho, estas palabras eran una bofetada para ellos y un latigazo en la espalda. Todas las ocurrencias de Sócrates, que no eran más que eyecciones y secreciones de su ignorancia,

${ }^{14}$ Søren Kierkegaard, Los primeros diarios, Vol. I, trad. de María J. Binetti, México: Universidad Iberoamericana, 2011, p. 79 / SKS 17, 28, AA: 12.

15 J. G. Hamann, Recuerdos socráticos. Aesthetica in Nunce, Madrid: Hermida Editores, 2018, p. 60. 
les parecían tan terribles como los cabellos de la cabeza de Medusa, el cordón umbilical de la égida ${ }^{16}$.

Esta interpretación de la ironía socrática fue bienvenida como espada de batalla por el movimiento romántico. Por medio del ingenio, la ironía de los románticos buscó desmantelar los criterios que daban fundamento a la sociedad conservadora y a la filosofía racionalista, fueron los románticos los que ensayaron nuevos estilos literarios buscando producir el efecto socrático en sus lectores. En un tono combativo Friedrich Schlegel afirmó que "las novelas son los diálogos socráticos de nuestro tiempo. En esta forma liberal la sabiduría de la vida se ha puesto a salvo de la sabiduría académica" ${ }^{17}$.

Sin embargo, para los opositores del Romanticismo, la ironía exacerbada puede destruirlo todo, esto es lo que vio y combatió Hegel en diversos escritos y lecciones. Para el filósofo de Stuttgart, la ironía "puede fingirlo todo; pero da pruebas solamente de vanidad, de hipocresía y de insolencia. La ironía conoce su maestría sobre todo contenido, no toma en serio nada y juega con todas las formas" 18 .

Las últimas décadas del siglo XVIII y durante la primera mitad del siglo XIX estuvieron marcadas por este debate entre las distintas formas de racionalismo y sus críticos. Este debate ponía en juego no solamente el sentido racional de la filosofía sino dos modos de vida encontrados y que, en cierta medida, se disputaban el dominio de los ambientes culturales de toda Europa. Este es el contexto en el que Kierkegaard decide hacer su tesis universitaria Sobre el concepto de ironía en constante referencia a Sócrates. Como es sabido, la vida estudiantil de Kierkegaard se prolongó varios años, pues estaba más ocupado en una forma de vida más bohemia que en la terminación de sus estudios; sin embargo, a la muerte de su querido profesor Poul Martin Møller y la de su padre, ambos fallecidos en 1838, se propuso terminar sus estudios. Desde ese año y hasta la defensa de su tesis, el 29 de septiembre de 1841, Kierkegaard hizo un profundo análisis sobre la ironía socrática y su significación histórica. La ironía socrática no era, como lo pensaba Hegel, "una manera o un recurso de la conversación,

${ }^{16}$ Ibíd., p. 69.

17 Friedrich Schlegel, Fragmentos, trad. de Pere Pajerols, Barcelona: Marbot Ediciones, 2009, p. 30.

${ }^{18}$ G. W. Hegel, Lecciones sobre bistoria de la filosofía, vol. III, trad. de Wenceslao Roces, México: Fondo de Cultura Económica, 1985, p. 482. Para este punto puede ahondarse en Jaffrey Reid, The Anti-Romantic. Hegel Against IronicRomanticism, London: Bloomsbury, 2014. 
a que se recurre para animarla un poco"19. En el análisis de Kierkegaard la ironía juega un papel muy importante en la transformación de una época. En el caso concreto de Sócrates, su ironía alcanzó no solamente a los usos racionales de los sofistas, sino también a la caída de la concepción helénica respecto de la apacible armonía del espíritu griego. Sócrates fue un pez torpedo para sus interlocutores, pero fundamentalmente para toda su época, de ahí el malestar que causaba y el que fuera acusado de corromper a la juventud. Por estos motivos, Kierkegaard afirma de Sócrates:

Toda la realidad dada había perdido validez para él, se había vuelto extraño a toda la realidad de lo sustancial. Este es uno de los aspectos de la ironía; pero el otro aspecto es que al aniquilar el helenismo utilizó la ironía; su actitud hacia el helenismo fue siempre irónica; siendo un ignorante y sin saber nada, buscó siempre la dilucidación en los otros, e hizo que lo establecido se derrumbara precisamente al dejarlo subsistir ${ }^{20}$.

El individuo verdaderamente irónico se ha salido de las filas de la contemporaneidad y es capaz de observar cómo la realidad está llena de fisuras y de inconsistencias. Si bien para sus contemporáneos el individuo irónico se vuelve un sujeto perturbado e incluso melancólico, pues no acepta lo que los demás dan por legítimo, por otra parte, ese distanciamiento lo vuelve libre respecto a las ataduras con las que esa realidad dominante encadena y enajena a la sociedad. Esta libertad le proporciona una forma de entusiasmo en su tarea como ironista, pues desde lo profundo de su personalidad y sus cualidades puede contribuir a que el orden establecido se muestre en toda su imperfección. Esta es la relevancia que tiene Sócrates para su momento histórico, pero también lo que se puede aprehender de él en otras épocas, en las que también existen categorías dominantes que producen un espantoso espejismo.

\section{Los alcances de la ironia kierkegaardiana}

Después de haber concluido su tesis, la vida de Søren Kierkegaard cambió en distintos sentidos; gracias a sus reflexiones sobre la ironía

${ }^{19}$ G. W. Hegel, Lecciones sobre historia de la filosofía, vol. II, p. 55.

${ }^{20}$ Søren Kierkegaard, De los papeles de alguien que todavía vive. Sobre el concepto de la ironía, trad. de Begonya Saez Tajafuerce y Darío González, Madrid: Trotta, 2000, p. 289 / SKS 1302. 
socrática tuvo una idea clara de que su vocación era la de ser un "escritor al servicio de la idea", como le gustaba decir. Sobre este hecho afirmó: "no he elegido yo la carrera de escritor; por el contrario, ella es una consecuencia de mi individualidad y de mi aspiración más profunda" ${ }^{21}$. Precisamente por la experiencia socrática y los dotes de su personalidad, su intención no era la de ser un escritor más, al modo tradicional del lenguaje filosófico, teológico o estético, sino que creó una forma peculiar de estilo, que era la combinación de comunicación indirecta, ironía y sinónimos, su verdadera intención era que sus lectores, y con ellos su época, comprendieran su verdadera situación, que reconocieran con honestidad aquellas "no verdades" en las que transcurría su vida y sus creencias.

Unas semanas antes de defender su tesis ya tenía la firme intención de romper su compromiso con Regina Olsen, le devolvió el anillo de compromiso el 11 de agosto de 1841, aunque el penoso proceso terminó hasta el 11 de octubre. Dos semanas después de la ruptura se va a Berlín durante casi seis meses, en los que trabaja intensamente en la redacción de su primera obra seudónima y sus discursos edificantes. Uno de los aspectos que posiblemente motivaron el rompimiento con Regina Olsen fue la visión clara de su vocación de escritor, pues vislumbraba todas las exigencias que su proyecto de "escritor al servicio de la idea" suponían para él. En efecto, los años siguientes fueron de una abundante producción de libros y discursos, con toda la riqueza literaria y la profundidad filosófica y literaria que contienen ${ }^{22}$.

En una anotación de su diario de 1845, Kierkegaard señaló un rasgo de su personalidad: "Existe un pájaro que se llama «augur de lluvias» [Regnspaaer]; yo soy como ese pájaro. En nuestra generación, cuando se prepara una tormenta, los individuos de mi clase aparecen"23.

$\mathrm{Al}$ igual que el ave que presagia las lluvias, el ironista tiene una cierta clarividencia respecto a la tormenta que se avecina; los vientos que la preceden provienen de diversos frentes. El primero de ellos es la pérdida del yo por medio de la masificación. Como Kierkegaard lo había asentado en la mencionada carta fechada en Gilleleje, es fácil observar a la masa de gente que, por indolencia espiritual o por un mal entendido egoísmo, vive

${ }^{21}$ Søren Kierkegaard, Papirer, SKS 20, 83, NB: 108.

${ }^{22}$ Esta intensidad en su vocación de escritor queda de manifiesto a menos de dos años de su rompimiento, durante 1843 Kierkegaard publicó seis libros: O lo uno o lo otro, Temor y temblor, La repetición y tres opúsculos que contenían un total de siete Discursos edificantes.

${ }^{23}$ Søren Kierkegaard, Papirer, SKS 18, 271, JJ:231. 
de la imitación de los demás. A esos seudo individuos que la conforman les parece más cómodo y útil ser uno más, transformando el yo individual en lo otro genérico. Este hombre masa tiene como único parámetro para medir el éxito o el fracaso su inclusión en los estándares generalizados y, si acaso logra sobresalir, lo es siempre dentro de esos parámetros comunes y casi nunca gracias a su carácter como verdadero individuo ${ }^{24}$.

Otro de los vientos que presagian la tormenta ya lo había señalado Kierkegaard en 1843, por medio del seudónimo Johannes de Silentio, en Temor y temblor. En esa obra llena de lirismo, señala en repetidas ocasiones que su época ha cancelado la pasión en beneficio de la ciencia ${ }^{25}$. El pensador danés vivió en una atmósfera triunfalista de la razón. Parecía que, en lugar de tormenta, el proyecto moderno auguraba una nueva era de dominio del hombre sobre la naturaleza y un progreso ilimitado por medio del desarrollo tecno-científico. Bajo esta ilusión de instalar el paraíso con nuestros medios temporales, se transformó el ideal humano; la tendencia masificadora del progreso técnico dejó a un lado la concepción espiritual del hombre; incluso fue peor, lo espiritual fue visto con recelo, como una fantasía perturbadora del progreso.

El otro viento que aparentaba una suave brisa pero que escondía los efectos destructores de una tormenta era la desacralización de la religión. La herencia hegeliana se hacía sentir por toda Europa. Esto aconteció también en el ámbito académico de Dinamarca, especialmente impulsado por J. L. Heiberg, quien desde una ramificación de la derecha hegeliana había promovido una transformación de la religión. La mediación racional hegeliana se estableció como paradigma para fundamentar las convicciones religiosas. Por eso Kierkegaard escribe: "la concepción que Hegel tiene del cristianismo carece en tal medida de esta originalidad de infantil interioridad que su planteamiento acerca de la fe - por ejemplo, de lo que significa creer-, no temo decir esto, es necedad pura" ${ }^{26}$. Cada vez con más convicción Kierkegaard se enfrenta a esta herencia hegeliana, con el estilo que lo caracteriza, en las páginas del diario de 1845 se encuentra el borrador de una sátira a Hegel titulada «La dialéctica del comienzo», en la cual dialogan Hegel y Sócrates sobre los fundamentos sin suposiciones de la filosofía. De cómo a partir de no suponer nada, Hegel logra la hazaña

${ }^{24}$ Cfr. Søren Kierkegaard, Los primeros diarios, p. 83 y p. 79 / SKS 17, 28, AA: 12.

${ }^{25}$ Søren Kierkegaard, La repetición. Temor y temblor, trad. de Darío González y Óscar Parcero, Madrid: Trotta, 2019, p. 109 / SKS IV 103.

26 Søren Kierkegaard, Papirer VI B 98: 45. 
de haber desarrollado un sistema ¡con 21 volúmenes!27 Un intento similar al de Descartes que, en su Discurso del método, después de haber dudado enérgicamente de todos los conocimientos de la filosofía precedente, a continuación, y en pocas páginas, desarrolla lo que considera el auténtico y definitivo fundamento de la filosofía y sus distintos saberes ${ }^{28}$.

La presencia de la ironía socrática recorre todos los escritos de Kierkegaard, no solamente en las referencias explícitas que hace al filósofo ateniense, sino también en el modo irónico de comunicarse con sus lectores. Me detendré como ejemplo de este recurso socrático en la obra seudónima La enfermedad mortal 29 . Del primer caso, la referencia directa a Sócrates, el seudónimo Anti-Climacus dedica todo un capítulo para explicar el concepto de falta en Sócrates, ahí hace una clara distinción entre la falta griega (socrática) y el pecado cristiano; no obstante esa diferencia, hace una importante valoración de la ironía: "Se opina que el mundo necesita una república, un nuevo orden social e, incluso, una nueva religión. Pero nadie piensa que de lo que más necesidad tiene el mundo, precisamente en virtud de tanto saber que confunde, es de otro Sócrates" ${ }^{30}$. Ayudado de esa ironía se muestra la inconsistencia de los que aparentan ser hombres justos, sabios o religiosos y que, sin embargo, actúan de manera contraria; el seudónimo afirma que cuenta con los parabienes de Sócrates al usar la ironía para que se hagan presentes sus contradicciones.

También en La enfermedad mortal podemos ver la ironía que hay en el desarrollo de su estudio sobre la desesperación. El planteamiento inicial del libro señala que la desesperación es una enfermedad universal, pero al mismo tiempo es una enfermedad ciega, ya que una gran parte de los que están desesperados no saben que lo están, o incluso afirman con toda su fuerza que no están desesperados ${ }^{31}$. Si esto es así, ¿cómo hacer ver al lector que él también es un desesperado y que la conciencia y aceptación de su situación es una ventaja cualitativamente superior que no estarlo? Tal vez el lector medio, al inicio de su lectura, pueda interesarse por el tema,

${ }^{27}$ Søren Kierkegaard, Papirer VI A 145.

${ }^{28}$ René Descartes, Discurso del método y Meditaciones metafísicas, trad. de Manuel García Morente, Madrid: Tecnos, 2002, p 94 ss.

${ }^{29}$ Tengo un estudio similar sobre la obra temprana de Kierkegaard, Temor y temblor. Cfr. "Seudónimos, ironía y comunicación indirecta", en Luis Guerrero, La verdad subjetiva. Søren Kierkegaard como escritor, México: Universidad Iberoamericana, 2004, pp. 75-88.

30 Søren Kierkegaard, La enfermedad mortal, trad. de Demetrio Gutiérrez Rivero, Madrid: Trotta, 2008, p. 121 / SKS 11, 205.

31 Ibíd., p. 43 / SKS 11, 138. 
para saber qué es la desesperación, pensando siempre que es algo que le acontece a los otros y no a él; o piensa, a lo sumo, que algunas veces ha estado desesperado por algún asunto específico, por una situación difícil en el trabajo, o por el dinero, la familia, la salud; por eso, tal vez el libro le resulte interesante, pues piensa que puede encontrar en él consejos para enfrentar esas situaciones y así poder dejar de estar desesperado. El lector comienza, entonces, a leer el libro. Aquí es donde entran en juego los muchos recursos de Kierkegaard para provocar una reacción en sus lectores: Además de la riqueza literaria de sus escritos, posee una dialéctica que muestra las distintas formas de desesperación, mediante observaciones que dejan al descubierto muchas formas de hablar y pensar ordinarias, todo esto para desmenuzar los distintos escondrijos en donde suele anidar, para no ser vista; esos escondrijos son situaciones que el lector identifica como lugares cercanos. En definitiva, lo que pareciera ser un libro que aborda un tipo de conocimientos, las distintas formas en las que puede darse la desesperación, es en realidad un examen de conciencia sobre la situación espiritual del lector. De esta forma la lectura del libro puede producir una profunda conmoción espiritual. Ya Aristóteles había señalado en su Poética la importancia de los efectos que un drama debe producir en el alma del espectador, pues es la fuerza del pathos lo que permite adentrarnos a ella, no simplemente como espectadores de las acciones que acontecen en la narración, sino viendo en ellas "incidentes que excitan piedad y temor" 32.

El efecto que suele producir la primera parte de La enfermedad mortal es el reconocimiento, por parte del lector, que él también es un desesperado; no en el sentido habitual del término -trabajo, dinero, familia, salud-, sino comprendiendo que esa desesperación proviene de no haberse enfrentado seriamente al fundamento más profundo de su existencia, y a la decisión de reconocer o no la realidad de ese fundamento. A partir de este efecto, la segunda parte de la obra plantea la desesperación como pecado, la consecuencia de haber construido los pilares de la vida alejados del único fundamento absoluto, del único poder fundante que es Dios; y los intentos desesperados por encontrar otro fundamento, el cual nunca termina de conseguirse.

Esta referencia a Dios nos introduce al aspecto central de las motivaciones de Kierkegaard como escritor. Como bien lo asienta en la introducción a El punto de vista sobre mi obra como escritor:

${ }^{32}$ Aristóteles, Poética, trad. de Valentín García Yebra, Madrid: Gredos, 1998, 1452a. 
El contenido de este pequeño libro afirma, pues, lo que realmente significo como escritor: que soy y he sido un escritor religioso, que la totalidad de mi trabajo como escritor se relaciona con el cristianismo, con el problema de "llegar a ser cristiano", con una polémica directa o indirecta contra la monstruosa ilusión que llamamos cristiandad, o contra la ilusión de que en un país como el nuestro todos somos cristianos $^{33}$.

Para este objetivo la ironía al modo socrático tiene un importante papel, provocar que la cristiandad se muestre como lo que es: "un terrible espejismo". Se trata de una vía negativa, el reconocimiento de la no verdad, para poder introducir el cristianismo dentro de la cristiandad.

Kierkegaard no intenta cristianizar a Sócrates pues, no obstante esta importancia socrática, en el ámbito de lo cristiano existe una clara distinción entre Sócrates y Cristo. Como se ha visto, la ironía al modo socrático puede contribuir al reconocimiento de la situación interior, al reconocimiento de la no verdad, de que se es egoísta a pesar de haber pensado que se era caritativo, de que el tesoro que se defiende con ahínco está en las cosas de este mundo, aunque muchas veces se haya expresado que su única confianza está en los bienes celestes; en definitiva, que la situación interior es desesperada, a pesar de la seguridad que se tiene ante las cosas del mundo. Sócrates reconoció siempre que él no poseía la verdad. En cambio, Cristo es la Verdad. Esto permite al cristiano tener un parámetro absoluto acerca de lo que hay que creer: Hay que creer en Cristo como Dios-hombre, pero también, y gracias a esa creencia, se tiene el parámetro de lo que realmente es la caridad, el pecado y el perdón, el sacrificio y la renuncia a lo mundano. Es gracias a esta nueva dialéctica: el reconocimiento de la no verdad, al estilo socrático, y el parámetro de la Verdad, en Cristo, que el individuo puede comprender su verdadera situación existencial.

La segunda obra del seudónimo Anti-Climacus, Ejercitación del cristianismo, nos introduce en la esfera de esta nueva dialéctica. Recuérdese que La enfermedad mortal busca llegar al reconocimiento del pecado, "la desesperación es el pecado" 34 ; como continuación de esta situación de pecado Ejercitación del cristianismo nos recuerda las palabras de Jesús: "Venid a mí todos los que estáis atribulados y cargados, que yo os aliviaré" 35.

33 Søren Kierkegaard, Mi punto de vista, trad. de José Miguel Belloso, Buenos Aires: Aguilar, 1980, p. 27 / SKS 16, 11.

${ }^{34}$ Søren Kierkegaard, La enfermedad mortal, p. 103 / SKS 11, 189.

35 Mt 11:28. Søren Kierkegaard, Ejercitación del cristianismo, trad. de Demetrio Gutiérrez Rivero, Madrid: Trotta, 2009, p. 33 / SKS 12, 21. 
Cristo es el salvador, sin embargo, esa invitación la realizó ante los demás desde la humildad, pues sus palabras las pronunció siendo un hombre al que había que creer; no fueron dichas desde la majestuosidad divina, sentado en el trono celestial. Creer en Jesús significa hacerse contemporáneo con él, lo que implica la posibilidad del escándalo, la necesidad de creer en un hombre que nació en la humildad de un pesebre, que vivió pobremente; quien, a pesar de sus acciones milagrosas, fue desacreditado y rechazado por las autoridades, así como abandonado por la muchedumbre, creer en aquel que fue condenado a morir en la cruz junto a dos malhechores. Incluso, esa creencia pasa por la creencia en el testimonio de aquellos que lo vieron resucitado y un día, también lo vieron ascender al cielo. La cristiandad, en cambio, hace a un lado la posibilidad del escándalo y se instala ufanamente como iglesia triunfante, gracias a la cual, la vida puede mantener un contubernio con la mundanidad y, gracias a esa fraudulenta asociación, "todos estos hombres, incluso los que insisten en que no hay un Dios, jtodos ellos son cristianos, se llaman a sí mismos cristianos, el estado los reconoce como cristianos, la iglesia los sepulta como cristianos, se gradúan como cristianos para la eternidad!"36

La intención de Kierkegaard es promover, ayudado por la ironía socrática, la reflexión del lector sobre su relación con la cristiandad. Estaba convencido que su época necesitaba pasar por un doble reconocimiento, de una parte, el reconocimiento de la verdadera situación de cada persona, sin querer aparentar aquello que no se es. Por la otra parte, el reconocimiento de Cristo como la verdad. Kierkegaard intentó en toda su producción como escritor poner al lector en condiciones de entender esta situación.

\section{Bibliografía}

Aristóteles, Poética, trad. de Valentín García Yebra, Madrid: Gredos, 1998.

Descartes, René, Discurso del método y Meditaciones metafísicas, trad. de Manuel García Morente, Madrid: Tecnos, 2002.

Hamann, J. G., Recuerdos socráticos. Aesthetica in Nunce, Madrid: Hermida Editores, 2018.

Guerrero, Luis, La verdad subjetiva. Søren Kierkegaard como escritor, México: Universidad Iberoamericana, 2004.

${ }^{36}$ Søren Kierkegaard, "La 'cristiandad' es un inmenso espejismo” / SKS 16, 24. 
Hegel, G. H., Lecciones sobre historia de la filosofía, Vol. II y III, trad. de Wenceslao Roces, México: Fondo de Cultura Económica, 1985.

Kierkegaard, Søren, Kierkegaards Skrifter (SKS), ed. por Niels Jørgen Cappelørn, Joakim Garff, Johnny Kondrup, Alastair McKinnon y Fin Hauberg Mortensen, Copenhague: Søren Kierkegaard Forskningscenteret ved Københavns Universitet, Gad Publishers, 1997-2013.

_ Søren Kierkegaards Papirer, ed. por P.A. Heiberg, V. Kuhr y E. Torsting, Copenhague: Gyndendalske Boghandel Forlag, 1909-1938.

"La 'cristiandad' es un inmenso espejismo", trad. de Leticia Valadez, Estudios Kierkegaardianos. Revista de Filosofía, no. 5, 2019.

—_Los primeros diarios, Vol. I, trad. de María J. Binetti, México: Universidad Iberoamericana, 2011.

- De los papeles de alguien que todavía vive. Sobre el concepto de la ironía, trad. de Begonya Saez Tajafuerce y Darío González, Madrid: Trotta, 2000.

— La repetición. Temor y temblor, trad. de Darío González y Óscar Parcero, Madrid: Trotta, 2019.

— La enfermedad mortal, trad. de Demetrio Gutiérrez Rivero, Madrid: Trotta, 2008.

— Ejercitación del cristianismo, trad. de Demetrio Gutiérrez Rivero, Madrid: Trotta, 2009.

— Mi punto de vista, trad. de José Miguel Belloso, Buenos Aires: Aguilar, 1980. Platón, Diálogos, V. II, trad. de Calonge, Acosta, Oliveri, Calvo, Madrid: Gredos, 1999.

— Diálogos, V. V, trad. de Santa Cruz, Vallejo, Cordero, Madrid: Gredos, 1998. Reid, Jaffrey, The Anti-Romantic. Hegel Against Ironic Romanticism, London: Bloomsbury, 2014.

Schlegel, Friedrich, Fragmentos, trad. de Pere Pajerols, Barcelona: Marbot Ediciones, 2009. 